\title{
A Re-Visit to the Concept of Sustainability
}

\author{
Guangwei Huang ${ }^{1}$ \\ ${ }^{1}$ Graduate School of Global Environmental Studies, Sophia University, Tokyo, Japan \\ Correspondence: Guangwei Huang, Graduate School of Global Environmental Studies, 7-1, Kioicho, Chiyoda-ku, \\ Tokyo, Japan. Tel: 81-3-3238-4667. E-mail: huang@genv.sophia.ac.jp
}

Received: June 11, 2014 Accepted: July 4, 2014 Online Published: August 10, 2014

doi:10.5539/enrr.v4n3p184 URL: http://dx.doi.org/10.5539/enrr.v4n3p184

\begin{abstract}
The concept of sustainability was re-examined from the perspectives of intra and inter-generational fairness. Case studies revealed that the apparent sustainable development of a city may turn out be the cause of un-sustainability of other cities or regions. Moreover, the notion that each generation should be entitled to environmental quality comparable to that enjoyed by previous generations was challenged with historical facts. Finally, a refined definition of sustainability was proposed.
\end{abstract}

Keywords: sustainability, intragenerational fairness, intergenerational fairness

\section{Introduction}

The concept of sustainability has been gaining increasing recognition and wide use both academically and politically in recent decades all around the world (Clark et al., 2004; van Kerkhoff \& Louis, 2006; Clark, 2007). Bringing society and the world's economy to a sustainable track presents the most significant challenge to the 21 st century. This challenge is unprecedented in scope targeting the planet as a whole. It requires a fundamental shift in consciousness as well as in action. It calls for innovative visions, new dreams and new approaches for shaping an evolving new reality.

Although the essence of the concept of sustainable development is clear, it has been followed by growing ambiguity with regard to interpretation and definition of sustainability. At present, scientific literature offers more than 100 definitions on sustainability or sustainable development (Pezzzoli, 1997).

The definition by Bruntland Commission, which is the most frequently cited, is that sustainable development is development that meets the needs of the present without compromising the ability of future generations to meet their own needs. The ambiguity of the definition causes the use of the concept a very broad spectrum of meaning often, to the point of trivialization. At the same time, the lack of certainty in sustainability concept allows different interest groups for having common ideological background. Furthermore, the ambiguity or uncertainty gives the concept more room for evolving. New knowledge and experience that affect understanding of problems and their solutions may be relatively easier to get incorporated into the framework. This is the reason that motivated the present study for further analysis of the sustainability concept.

Under the current development context, a big issue the sustainability science must address is the rapid and global increase in urbanization, which may be viewed either an opportunity or a challenge to the society. Over the past several decades, many sustainability studies were devoted to cities ranging from large ones such as London (Commission for a sustainable London, 2012; London Sustainable Development Commission, 2009), Tokyo (Fujita \& Richard, 2007; Jang et al., 2011), Montreal (Poitras, 2009), Barcelona (Domene et al., 2005), Shanghai (Chiu, 2012) and Hong Kong (Chiu, 2000) to medium and small cities such as Rotterdam (Frantzeskaki et al., 2014). Given the rapidly expanding world population and transition to predominantly urban societies, urban sustainability or sustainability in urban context is at the forefront of many discussions.

While governmental initiatives, action plans and research studies toward sustainable cities have greatly enriched the knowledge and understanding on what constitutes sustainability, they looked at sustainable development in an isolated manner or at a single scale, and failed in addressing a possibility that the sustainability of a city may be the cause of un-sustainability of other cities, or some cities may be sacrificed for a particular city being "sustainable". Although studies in the field of urban metabolism have revealed that urban dwellers depend on the productive and assimilative capacities of ecosystems well beyond their boundaries (Kennedy et al., 2011), much less attention has been paid to the inequality in regional development induced by large-scale urban sprawl. In view of such a 
shortcoming, the present study employed case study approach to examine how a city deemed on sustainable track might impact other cities or regions negatively.

\section{Methodology}

The present study employed case study approach to link between ideas and evidence. The attention was placed on both Japan and China. The logic is that nowhere was urbanization felt more keenly than in Japan during the 1960s and 1970s; and nowhere will this be felt more keenly than in China nowadays. In 1980, less than $20 \%$ of the Chinese population lived in cities, but this number is predicted to rise to $75 \%$ by 2030 . Mega cities in both countries such as Tokyo and Tianjing have been pursuing sustainable urban living with various initiatives although the start point of time differed. Tokyo is the world's largest urban economy in terms of GDP or gross metropolitan product (GMP) at purchasing power parity (PPP), while Tianjin became the city with the highest per capita income in China since 2011. Besides, the Chinese government currently plans to transform the city into one of the world's leading financial centers. Therefore, lessons learned from the two models for building a sustainable city may serve for future urbanization efforts in many emerging countries.

Since sustainability deals with human-environment interaction that may be characterized by many different indicators, this study used population in Japanese case and GDP in Chinese case as surrogate for human society and water as a representative of the essential natural environment to human beings in both cases for simplicity and clarity. In the discussion of intergenerational fairness, the attention was placed on the recovery from chaotic situations. Besides, Gini index was used to shed light on the difference between global and regional intergenerational fairness. By highlighting hidden or insufficiently explored issues with regard to unbalanced development in cases considered, and re-analyzing the sustainability concept from the perspectives of intra and inter-generational inequality, it was attempted to refine the definition of sustainability by Bruntland.

\section{Problem Identification}

\subsection{Issue 1: Unfairness Within the Present Generation}

The core sustainability principal of meeting the needs of the present without affecting the ability of future generations appears largely macro and emphasizing intergeneration fairness. It is viewed as a paradigm upon which future policies must be based. However, should the fair use of natural and human resources and fair distribution of wealth among the present generation of people or efforts toward the fair use and distribution be understood as a presumption to the widely used definition of sustainability? This principle could probably be agreed upon by everyone, but the reality could be a different matter.

Japan is one of the world's most efficient countries in the use of industrial energy. Japanese manufacturers lowered energy consumption per unit of output by 40 percent between 1973 and 2003. It also ranks near the bottom among developed countries in $\mathrm{CO}_{2}$ emissions per capita and GDP ratio. In the OECD, only Sweden has lower $\mathrm{CO}_{2}$ emissions to GDP ratio than Japan (Agency for Natural Resources and Energy of Japan, 2005). However, Japan has been facing a serious social crisis since 2007. Its population is shrinking at a record pace. In 2011, the total fertility rate - the average number of babies a woman gives birth to during her life - was 1.39 (Statistics Bureau of Japan, 2014). A total fertility rate of 2.07 is required to maintain population levels (Cabinet Office of Japan). Because Japan's economy and social systems were structured on the premise of population growth, the depopulation will have a big impact on the workforce making it difficult to maintain the social security systems such as pension benefits and medical insurance.

Tokyo, as one of the world's largest megalopolis, however is an exception among Japanese cities to the depopulation trend. Tokyo has made great efforts toward being a sustainable city. It generates only 5 percent of the nation's $\mathrm{CO}_{2}$ emissions despite 17 percent of Japan's GDP. As shown in Fig. 1, the population in Tokyo was very stable in the 1980s and the 1990s, and even increased from 12.06 million to 13.189 million during the period from 2001 to 2011. Nevertheless, the fertility rate in Tokyo had declined from 1.44 to 1.24 in the 1980s and has been lower than 1.2 since 1991. Therefore, the population stability in Tokyo is due to the population influx from other regions.

Between 2000 and 2005, the Tokyo region added 1.1 million new residents, while the rest of the nation lost 200,000 residents. The imbalance became even starker between 2005 and 2010, as Tokyo added 1.1 million new residents, while the rest of the nation lost 900,000.

In light of the above facts, the population of Tokyo is sustained at the cost of depopulation of other regions. Wording differently, the sustainability of Tokyo might be considered as the cause of un-sustainability of other regions. 


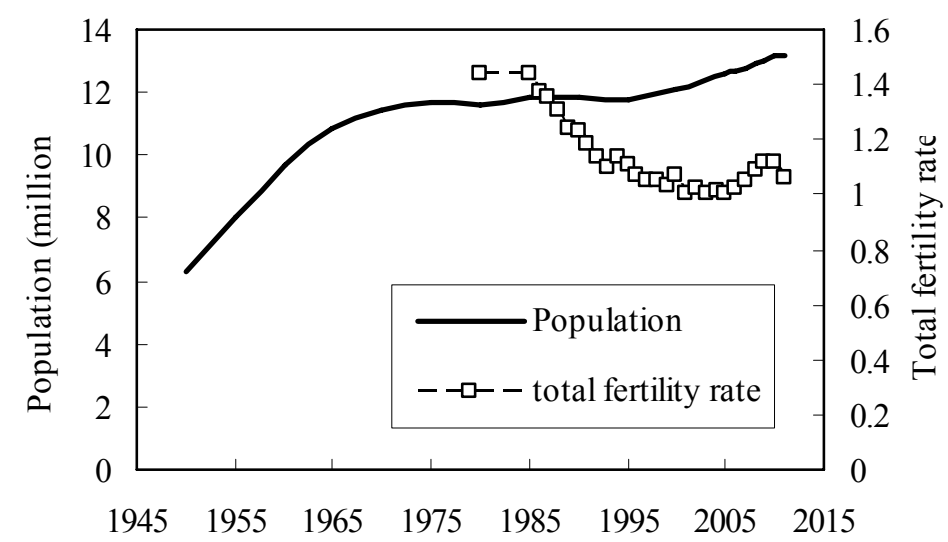

Figure 1. Changes of the population and birth rate in Tokyo

Most of the water resources of Tokyo come from rivers. The share of the water from rivers is as follows: $78 \%$ from the Tonegawa and Arakawa River systems and 19\% from the Tama River system.

Tone River originally flowed into Tokyo Bay through the city of Edo. In the 17th century, the river course was diverted to the Pacific Ocean for a number of reasons. One of them was to protect the city of Edo from flooding. With the completion of the diversion project, the watershed of Lake Tega, which was not related to the Tone River in anyway before the diversion project, became a retarding basin for flood waters from the Tone River. In the 18th century, many efforts were made for farmland development around the lake, but all failed because of frequent flooding (Tanikawa \& Aihara, 2005). There are other similar sites such as Tanaka retarding basin in the downstream reaches of the Tone River. The flood risk in Tokyo was partially shifted to other areas via engineering works.

Tokyo is also well known as one of the best public transit serviced cities in the world. It combines an extensive train network, underground subway lines and a bus system. The percentage of public transport use in Tokyo is $65 \%$ (Institution for Transport Policy Studies, 2003). The Yamanote Line is a railway loop line in Tokyo, operated by East Japan Railway Company (JR East). It is one of Tokyo's busiest and most important lines, connecting most of Tokyo's major stations and urban centers. During peak times, the electricity for running the train is generated from a hydro-power station in the middle reaches of the Shinano River, which is located in the Niigata Prefecture, more than $200 \mathrm{~km}$ away from Tokyo. Huang (2005) reported that the operation of the hydro-power station caused thermal anomaly in the river reaches downstream of the hydro-power station, not to mention the huge change in flow regime. The sustainable transport system in Tokyo carries an environmental cost paid by another region.

Tianjin is the sixth largest city of China having a population of more than 11.7 million. It is one of the most important industrial bases in Northern China and it has developed an industrial system ranging from steel, chemical, and textiles to automobile. Tianjin's urban area is the third largest in the country covering $11,917 \mathrm{~km}^{2}$. Farmland takes up about $40 \%$ of Tianjin Municipality's total area. Wheat, rice, and maize are the main crops and fishery is important along its coast. Tianjin has boasted a large portion of oversea trading and foreign investment in its dynamic economy. More than 125 companies of the world top 500 have invested in Tianjin, and Tianjin is renowned for its high rate of return. In 2011, Tianjin recorded China's highest per-capita GDP with $\$ 13,393$, surpassed Shanghai and Beijing, and also took the first place by GDP among the 31 province-level regions in mainland China in 2012 and 2013.

According to Tianjin City Master Plan (2005-2020), authorized by State Council in 2006, the city is aimed to be an international harbor city, economic center in the north of China and an eco-city. However, the city does not have sufficient water resources within its administrative boundary due to natural geographic and climatic condition. The average annual precipitation in Tianjin is about $550 \sim 680 \mathrm{~mm}, 75 \%$ of which is concentrated in June, July and August. The water availability per capita in Tianjin is $160 \mathrm{~m}^{3}$, which is $1 / 15$ of the national average, and much lower that the water scarcity level defined by UN, which is $1000 \mathrm{~m}^{3}$.

To alleviate the water scarcity problem, a project to transfer water from the Luan River to Tianjin was implemented in 1981 and completed in 1983. It supplies 1 billion $\mathrm{m}^{3}$ of additional water to the city in a relatively dry year, which is about $65 \%$ of Tianjin's own total annual renewable water resources. Therefore, there is no doubt that the diversion has been serving as a driving force for the economic development in Tianjin. Nevertheless, the diversion project caused significant change in the downstream reaches of the Luan River. 
Luan River flows northwards from its source in the province of Hebei into the province of Inner Mongolia, and then turns southeast back into Hebei to its mouth on the Bohai Sea. The catchment area is $44,900 \mathrm{~km}^{2}$ and the main channel length is $888 \mathrm{~km}$.

After the diversion, the mean annual runoff in the downstream of the Luan River decreased from $47.2 \times 10^{8}$ to $18.4 \times 10^{8} \mathrm{~m}^{3}$ (Qian, 1994). Due to the reduction of flow, flood plains in the downstream were easily converted to farmlands as shown in Fig. 2, which increased the water use for agriculture in the downstream. As a result, the annual runoff into the sea from the river almost ceased since 2000 in normal years. In 2003, the number of zero flow days exceeded 200. Meanwhile, the sediment flux from the river to the sea during the period of 2000- 2009 decreased 483.6 times as compared to the sediment flux in 1950- 1959, leading to severe coastal erosion (Xue et al., 2009). Another related issue is that salt water intrusion increased from $7.98 \mathrm{~km}$ to $9.62 \mathrm{~km}$, causing high soil salinity around the river mouth (Zhou et al., 2011).

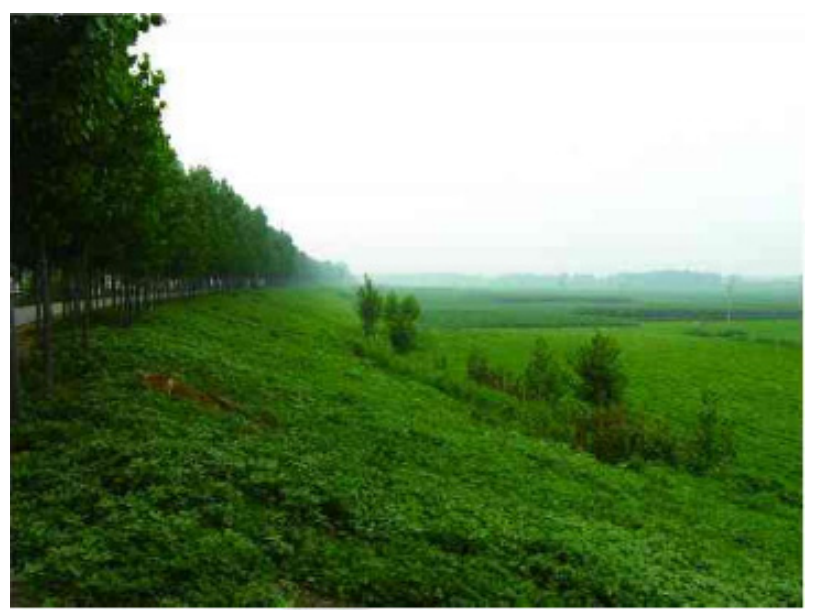

Figure 2. Cropland developed on the floodplains of the downstream reaches of Luan River

The lesson from the two cases is that a sustainable urban development may inflict on the ecological integrity of other regions.

\subsection{Issue 2: Intergeneration Fairness}

Sustainable development is inherently both an intragenerational question and intergenerational question. The theory of intergenerational equity states that all generations have an equal place in relation to the natural system, and that there is no basis for preferring past, present or future generations in relation to the system (Weiss, 1992). The emphasis in the concept is for subsequent generation to receive the planet in no worse condition as compared to previous generation in terms of natural and cultural resources, and the equitable access to the use and benefits of the legacy. This notion has deep roots in international law.

However, it ignores the evolution and fluctuation of the natural environment, human nature and human's capacity of innovation and adaptation. Nature can be hostile to human beings during certain period of time. For example, the volcanic eruption destroyed the Roman cities of Pompeii and Herculaneum In the year of AD 79. China suffered 291 droughts from the 15th century to the 18th century, leading to the overturn of the Ming Dynasty. On March 11, 2011, the world witnessed the horrible power of Tsunami devastating the Tohoku region of Japan. Moreover, human society evolution has been defined by conflict; its history may be characterized as the history of war. On the other hand, the development of new energy sources such as solar and wind power generations and genetically modified crops are the manifestation of mankind's ability to develop a new and innovative relation with the nature.

War is destructive to the environment and social sustainability. As World War II had ended in 1945, Japan was devastated. All the large cities (except Kyoto), the industries and the transportation networks were severely damaged. A severe shortage of food continued for several years. Then, Japan's "economic miracle" occurred for several reasons. First, United States invested millions in aid to restore Japan's economy and it has assumed responsibility for defending Japan so that he Japanese government spends very little on defense. Second, the Korean War triggered global economic changes that served Japan well. At the time, Japan was the only 
industrialized country with spare engineering capacity, and orders poured in for its machine products. Because Western shipyards were fully extended, the country was presented with a golden opportunity to develop its shipbuilding industry as a leading export sector (Nakagawa, 1992). Japan was also allowed to participate in and so profit from the U.S.-directed reconstruction of South Korea. Last, the management style, high self-esteem and pride of employees in their work and high tech business climate contributed to the economic re-building.

In China, the Cultural Revolution, launched in 1966 and lasted for 10 years, had a massive impact on the people and the economy of China. For the entire decade of the Cultural Revolution, schools in China stopped functioning or did not operate normally, which left an entire generation with no formal education. Millions of educated youths were sent to rural areas to work in the countryside. Many of the professional people had also been targets for reeducation and were dispersed across the countryside, working in labor camps. Due to the elimination of qualified teachers, some counties in China had illiteracy rates as high as $41 \%$ some 20 years after the revolution (Peterson, 1997). The decade-long political unrest resulted in severe setback in economic and societal development in China, which was inevitably passed down to the subsequent generation.

After the chaos, the suffering and almost-collapsed economy, however, became a trigger for the whole country to rush for economic reform and development. Since then, it becomes the world's fastest-growing economy, with growth rates averaging $10 \%$ over the past 30 years. Nowadays, China is the world's second largest economy by nominal GDP and by purchasing power parity after the United States.

War and political unrest cause not only human tragedy and economic loss, buts also ecological consequences which could be long lasting. One example was the dropping of the atom bomb on two Japanese cities at the end of the 2nd world war. Both Hiroshima and Nagasaki cities were quickly recovered for the grievous wounds and now are as livable as any other cities in Japan. Although the reason for the quick recovery may deserve further in-depth analysis, it is the evidence that both nature and human society can recover from war or unrest in general if not completely.

The reviving stories of both Japan and China indicate that a negative legacy might turn out to be a mechanism for a greater release of positive energy from the subsequent generation. Therefore, the ability that the future generation should possess is not just the ability to meet their needs under favorable conditions but also the ability to turn a bad situation into a good one.

\subsection{The Difference Between Global and Regional Intergenerational Fairness}

Gini index measures the extent to which the distribution of income among individuals or households within an economy deviates from a perfectly equal distribution. A Gini index of 0 represents perfect equality, while an index of 1 or 100 implies perfect inequality. It is the most commonly used measure of the amount of income inequality in a society.

Figure 3 show the change of the global Gini index from 1961 to 2010. The values from 1961 to 1989 were calculated by Milanovic (2005), and the results for the period of 1990-2010 were calculated by The Conference Board of Canada using World Bank (2014) data for 172 countries for which data on per capita income were available. The Conference Board data were adjusted to account for differences in country coverage and data between Milanovic's study and that of the Conference Board. The changes of the Gini index for Indonesia and the child poverty rate in Japan were also plotted in the same figure. A child is deemed to be living in relative poverty if he or she is growing up in a household where disposable income, when adjusted for family size and composition, is less than $50 \%$ of the median disposable household income for the country concerned. As seen from the figure, the world inequality past its peak at the beginning of the 2000s, and has been dropping consistently since then. In spite of the global trend, the inequality in Indonesia has been increasing over the past decade. The income inequality in other developing countries such as Nepal, Cambodia and India was also reported to have widened from the 1990s to 2000s (Asian Development Bank, 2007). Such an inconsistency between the global and regional trends in social development was originated from intragenerational inequality and passed on as an intergenerational issue. Besides, such a cascading process from intragenerational to intergenerational inequality is not limited to developing countries. As also shown Fig. 3, the child poverty rate in Japan is on the rise although Japan is one of the world's major economies. Japan has a saying "ichioku-sohchu-ryu" which translates to "a nation of middle-class people." However, over the last few decades, the middle-class in Japan has been shrinking, and incomes have dropped for the lower classes while they've risen for those in the higher classes. And one of the consequences is the rise of the child poverty rate. As such an intragenerational inequality is persistently developed, it propagates to the next generation causing intergenerational inequality and the intergenerational inequality may further increase the intragenerational inequality forming a vicious cycle. Thus, the burden of problem-solving inevitably falls on the shoulders of future generations. 
A problem with Gini index is that many high-income residents do not want to take the survey of income disparity, and census authority cannot guarantee that substitutes have the same level of income, causing part of the high-income group to be omitted. Besides, those high-income survey-takers may not provide a full picture, especially when they have significant grey income, or income from extralegal sources. Therefore, Gini index based on reported income could be underestimated. How the accuracy of Gini index affects the discussion on intergenerational and intergenerational inequalities deserves further in-depth analysis.

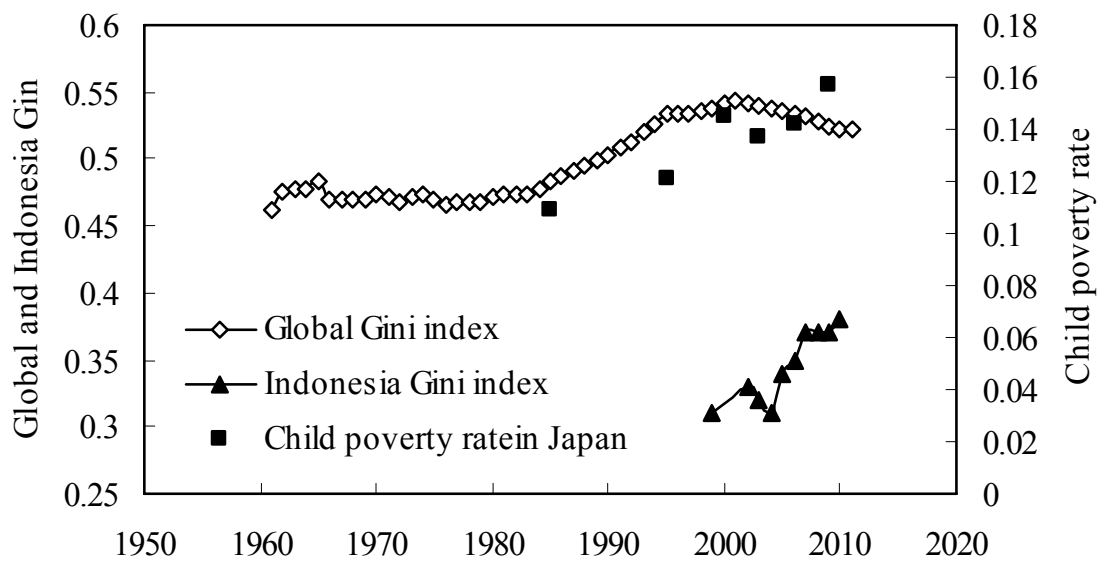

Figure 3. Changes of global Gini index, Indonesia Gini index and child poverty rate of Japan (Source of data for Indonesia and Japan: OECD)

\section{Concluding Remarks}

The sustainability of a city or a region does not guarantee the sustainability of a larger region or a nation. It is not difficult to image that the sustainable development of a large city may be at the cost of degradation of other cities or areas because of the influx of both natural and human resources into that city from other cities or areas. The present study provided concrete evidences that a city on sustainable development track may cause negative effects in areas far away from its administrative boundary. And such a story is not limited to developing or emerging country. On the other hand, the global sustainability does not ensure the sustainability of all regions. Judging by the Gini index, the current status of global sustainability is out of phase with the regional sustainability level in Asia. Moreover, the present study also pointed out that the capacity of human beings to recover from sufferings may need to be given more attention in the study of sustainability. Based on these findings, the definition of sustainability by Bruntland may be expanded as follows

"Sustainable development is development that meets the needs of the present without compromising the ability of future generations to meet their own needs. However, the needs of the present should be addressed in a politically fair, disparity-concerned and resources-minded way. The ability of future generation does not just mean the ability to continue what is on the right track, but also the ability to solve problems left by previous generations and recover from a disturbed state". By adopting this definition, new research initiatives investigating spatial and temporal patterns of sustainable development shall be promoted, which may result in new framework in sustainability science.

\section{References}

Agency for Natural Resources and Energy of Japan. (2005). White Paper on Energy.

Asian Development Bank. (2007). Inequality in Asia-Key Indicators. 2007 Special Chapter- Highlights.

Cabinet Office of Japan. (2001). White Paper on National Life.

Chiu, R. L. H. (2000). Environmental Sustainability of Hong Kong's Housing System and the Housing Process Model. International Planning Studies, 5(1), 45-64. http://dx.doi.org/10.1080/135634700111819

Chiu, R. L. H. (2012). Urban Sustainability and the Urban Forms of China's Leading Mega Cities, Beijing, Shanghai and Guangzhou. Urban Policy and Research, 30(4), 359-383. http://dx.doi.org/10.1080/08111146. 2012.737578 
Clark, W. C. (2007). Sustainability science: A room of its own. Proceedings of the National Academy of Sciences, 104(6), 1737-1738. http://dx.doi.org/10.1073/pnas.0611291104

Clark, W. C., Crutzen, P. J., \& Schellnhuber, H. J. (2004). Science for global sustainability: Toward a new paradigm, In H. J. Schellnhuber, P. J. Crutzen, \& W. C. Clark (Eds), Earth System Analysis for Sustainability (pp. 1-28). Cambridge, Ma: MIT Press.

Commission for a sustainable London 2012. (2010). A snapshot review of sustainability and transport across the London 2012 programme. Retrieved from http://www.cslondon.org/publications//?category=1\&did=58

Domene, E., Saurí, D., \& Parés, M. (2005). Urbanization and Sustainable Resource Use: The Case of Garden Watering in the Metropolitan Region of Barcelona. Urban Geography Volume, 26(6), 520-535. http://dx.doi.org/10.2747/0272-3638.26.6.520

Frantzeskaki, N., Wittmayer, J., \& Loorbach, D. (2014). The role of partnerships in 'realising' urban sustainability in Rotterdam's City Ports Area, The Netherlands. Journal of Cleaner Production, 65, 406-417. http://dx.doi.org/10.1016/j.jclepro.2013.09.023

Fujita, K., \& Richard, C. H. (2007). The zero waste city: Tokyo's quest for a sustainable environment. Journal of Comparative Policy Analysis: Research and Practice, 9(4), 405-425.

Huang, G. W. (2005). Signature of Human-Caused Alterations of In-Stream Thermal Environment. J. Hydrau., Coast. Environ. Eng., JSCE, No.796/II, 113-117.

Institution for Transport Policy Studies. (2003). City Transportation Year Book for 2003.

Jang, Y. J., Go, J. Y., \& Lee, S. (2009). Evaluating integrated land use and transport strategies in the urban regeneration projects toward sustainable urban structure: case studies of Poitras, C. Designing sustainability for whom? Recent housing developments in Southwest Montréal. Local Environment: The International Journal of Justice and Sustainability, 14(6), 515-528.

Jang, Y. J., Go, J. Y., \& Lee, S. (2011). Evaluating integrated land use and transport strategies in the urban regeneration projects toward sustainable urban structure: case studies of Hafen City in Germany and Shinagawa Station in Tokyo. International Journal of Urban Sciences, 15(3), 187-199. http://dx.doi.org/10.1080/12265934.2011.635882

Kennedy, C., Pincetl, S., \& Bunje, P. (2011). The study of urban metabolism and its applications to urban planning and design. Environmental Pollution, 159(8-9), 965-1973. http://dx.doi.org/10.1016/j.envpol.2010.10.022

London Sustainable Development Commission. (2009). London's Quality of Life Indicators. 2008-09 Report.

Milanovic, B. (2005). Worlds Apart: Measuring International and Global Inequality (pp. 180-181). New Jersey, USA: Princeton University Press.

Nakagawa, K. (1992). Postwar Ocean Shipping and Shipbuilding in Japan-Struggle in the 1950s. Nihon Kezai Hyouronsha Ltd. (in Japanese).

Peterson, G. (1997). The Power of Words: literacy and revolution in South China, 1949-95. Vancouver, BC: UBC Press.

Pezzzoli, K. (1997). Sustainable development: A transdisciplinary overview of the literature. Journal of Environmental Planning and Management, 40, 549-574. http://dx.doi.org/10.1080/09640569711949

Qian, C. (1994). Effects of the Water Conservation Projects in the Luanhe River Basin on Luanhe Delta, Hebei Province. Acta Geographica Sinica, 49(2), 158-166 (in Chinese).

Statistics Bureau of Japan. (2014). Japan Statistical Yearbook 2014.

Tanikawa N., \& Aihara, M. (2005). Historical geography surveillance study which cared about regional formation of the Tega Lake reclamation by drainage. Proceedings of the Research Institute of Social System, Chou Gakuin University, 5(2), 217-236 (in Japanese).

The Conference Board of Canada. (ND). Retrieved from http://www.conferenceboard.ca/hcp/hot-topics/ worldinequality.asp $x$

van Kerkhoff, L., \& Louis, L. (2006). Linking knowledge and action for sustainable development. Annual Review of Environment and Resources, 31, 1-33.

Weiss, E. B. (1992). In Fairness to Future Generations and Sustainable Development. American University International Law Review, 8(1), 19-26. 
Xue, Z., Feng, A., Yin, P., \& Xia, D. (2009). Coastal Erosion Induced by Human Activities: A Northwest Bohai Sea Case Study. Journal of Coastal Research, 25(3), 723-733. http://dx.doi.org/10.2112/07-0959.1

Zhou, Z. M., Han, Z., \& Guo, X. (2011). Evaluation of seawater intrusion and Prevention countermeasures in Luan River Irrigation District. China Rural Water and Hydropower, 8, 5-8 (in Chinese).

\section{Copyrights}

Copyright for this article is retained by the author(s), with first publication rights granted to the journal.

This is an open-access article distributed under the terms and conditions of the Creative Commons Attribution license (http://creativecommons.org/licenses/by/3.0/). 